\section{Case Reports in Ophthalmology}

\begin{tabular}{l|l}
\hline DOI: $10.1159 / 000486922$ & P 2018 The Author(s) \\
Published online: February 8, 2018 & $\begin{array}{l}\text { Published by S. Karger AG, Basel } \\
\text { www.karger.com/cop }\end{array}$ \\
\hline
\end{tabular}

This article is licensed under the Creative Commons Attribution-NonCommercial-

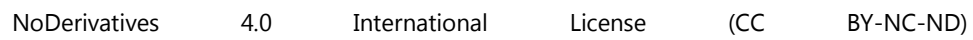
(http://www.karger.com/Services/OpenAccessLicense). Usage and distribution for commercial purposes as well as any distribution of modified material requires written permission.

\title{
Ocular Injury due to Potassium Permanganate Granules
}

\author{
Chareenun Chirapapaisan $^{a} \quad$ Pinnita Prabhasawat $^{a}$ \\ Sabong Srivannaboon ${ }^{a} \quad$ Vatookarn Roongpoovapatr $^{b}$ \\ Piyada Chitsuthipakorn ${ }^{c}$ \\ ${ }^{a}$ Department of Ophthalmology, Faculty of Medicine Siriraj Hospital, Mahidol University, \\ Bangkok, Thailand; ${ }^{b}$ Department of Ophthalmology, Mettapracharak (Wat Raikhing) \\ Hospital, Bangkok, Thailand; 'Department of Ophthalmology, Sawanpracharak Hospital, \\ Nakhon Sawan, Thailand
}

\section{Keywords}

Potassium permanganate $\left(\mathrm{KMnO}_{4}\right) \cdot$ Granules $\cdot$ Ocular injury $\cdot$ Burn

\begin{abstract}
Purpose: We report a rare case of ocular injury due to potassium permanganate $\left(\mathrm{KMnO}_{4}\right)$ granules in a child. Methods: This is a retrospective case report. Results: A 2-year-old boy was transferred to our emergency room with severe pain in his right eye, inflamed eyelids, and brownish stains on his fingers. Chemical injury was suspected. Copious eye irrigation was immediately performed. Diffuse brownish splotches were then observed at the inferior bulbar conjunctiva. Otherwise, systemic organs were intact. Complete eye exam under general anesthesia revealed a $5-\mathrm{mm}$ epithelial defect at the central cornea, along with generalized conjunctival injection and limbal ischemia, inferiorly. Multiple semi-dissolved granules of $\mathrm{KMnO}_{4}$ trapped in the inferior fornix were identified. The chemical particles were gradually washed out and removed; however, the brownish stains remained. The patient received preservativefree steroid, antibiotic eye drops, and lubricants as regular management for mild to moderate degree of ocular burn. Pseudomembrane developed early and transformed into symblepharon within a few days after the injury. Membrane adhesion was lysed, and more aggressive medications were then substituted. Commercial amniotic membrane (PROKERA ${ }^{\circledR}$ ) was
\end{abstract}




\section{Case Reports in Ophthalmology}

Case Rep Ophthalmol 2018;9:132-137

DOI: $10.1159 / 000486922$

also applied to promote wound healing and to prevent recurrence of symblepharon. The ocular surface was eventually restored, and corneal transparency was preserved. Conclusion: Ocular injury with the granular form of $\mathrm{KMnO}_{4}$ is rare. Its toxicity is comparable to concentrated $\mathrm{KMnO}_{4}$ solution. However, the dissolved particles that had been absorbed in the stained conjunctiva were continuously released and damaged the ocular surface more than we primarily anticipated. Awareness of this condition and prompt management yield a good treatment outcome.

(C) 2018 The Author(s)

Published by S. Karger AG, Basel

\section{Introduction}

Potassium permanganate $\left(\mathrm{KMnO}_{4}\right)$ is a chemical compound that has strong oxidizing properties. It decomposes immediately when encountering acidic or basic solutions and then produces reactive products varying in acid-base properties depending on the type of soluble media. Although $\mathrm{KMnO}_{4}$ is typically classified as a salt, its dissolved form in the water has basic properties (pH 7.2-9.7 at the concentration of $20 \mathrm{~g} / \mathrm{L}$ at $20^{\circ} \mathrm{C}$ ) [1].

$\mathrm{KMnO}_{4}$ has several uses, including medical therapy as an antiseptic or disinfectant for particular types of dermatitis, such as fungal infection of the hands and feet; as an industrial wastewater treatment; as a chemical reagent in laboratories; and as an agent for preserving fruits and vegetables at home [2]. $\mathrm{KMnO}_{4}$ is typically supplied as dry, crystal-like, dark purple granules that are added to water to create a $\mathrm{KMnO}_{4}$ solution before use. As a compound substance, $\mathrm{KMnO}_{4}$ will be disassembled into potassium and permanganate ions in a chemical reaction, ready for oxidizing other substances, which take up 1 of these 2 ions. Like other reactive agents, the chemical properties of $\mathrm{KMnO}_{4}$ make it toxic to human tissue when it comes into contact with skin or mucous membrane. Tissue affected by $\mathrm{KMnO}_{4}$ would be burned and brownish-colored [3]. The severity of injury varies according to the route and organ of injury, the amount and concentration of $\mathrm{KMnO}_{4}$, and the duration of tissue-chemical agent contact. Although widespread household use of $\mathrm{KMnO}_{4}$ has decreased in popularity over the years, the common use of $\mathrm{KMnO}_{4}$ at home continues in some countries. Previous articles described $\mathrm{KMnO}_{4}$ toxicity to the skin, mucous membranes, and eyes [3, 4]. Most reported $\mathrm{KMnO}_{4}$ injuries were caused by contact with different concentrations of $\mathrm{KMnO}_{4}$ solution. Here, we report a rare case of ocular injury in a child who accidentally came in contact with a granular form of $\mathrm{KMnO}_{4}$, which caused a burning reaction similar to that seen in people with chemical burns by highly concentrated $\mathrm{KMnO}_{4}$ solution.

\section{Case Presentation}

A 2-year-old boy was transported to our emergency department with excruciating pain in his right eye. Prior to injury, he had been left playing alone near a storeroom, which kept all cleaning substances, including an unwrapped $\mathrm{KMnO}_{4}$ crystal bag, while his mother was working in the backyard. His mother rushed back into the house when she heard his scream, and then she brought him to the hospital at once. At the emergency room, primary physical exam revealed stable vital signs. Only swollen right eyelids and tears were markedly apparent. Brown-colored staining was also observed on his hands and fingers. A chemical ocular injury in the right eye was suspected. Consistent with standard treatment guidelines, copious eye irrigation with normal saline was immediately performed. A universal indicator was used to check the $\mathrm{pH}$ of the ocular surface. The $\mathrm{pH}$ level was 7.0 after $4,000 \mathrm{~mL}$ of saline irri- 


\section{Case Reports in Ophthalmology}

Case Rep Ophthalmol 2018;9:132-137

DOI: $10.1159 / 000486922$

gation. Brown splotches were noted at the inferior bulbar conjunctiva through the lower fornix, but they could not be flushed out.

A complete ophthalmic exam was performed under general anesthesia in the operating room. A 5-mm epithelial defect (ED) was discovered at the central cornea. Fortunately, the stroma underneath was slightly edematous but not opaque. The inferior limbus from 4 to 8 o'clock was swollen and blanching. Multiple semi-dissolved granules of potassium permanganate were found trapped in the lower fornix (Fig. 1), resulting in scattered brown patches over the inferior bulbar and tarsal conjunctiva. All granules were delicately removed and the whole ocular surface was thoroughly irrigated, particularly in the inferior fornix. However, some stains remained on the conjunctiva (Fig. 2). The patient received 1\% dexamethasone eye drops every $2 \mathrm{~h}$, levofloxacin eye drops 4 times a day, preservative-free tears every hour, and tobramycin-dexamethasone eye ointment at bedtime. The causative agent was later presumed to be $\mathrm{KMnO}_{4}$ by the patient's mother, bringing spilled-out granules from the ransacked $\mathrm{KMnO}_{4}$ bag she had found in the house to the hospital.

The following day, the corneal ED was almost closed. All $\mathrm{KMnO}_{4}$ stains had disappeared, with a remaining mild degree of conjunctival injection. Fluorescein solution was applied over the ocular surface to identify the extent of injury. Apart from the corneal ED, we found that the limbus and conjunctiva had also sustained chemical toxicity. A punctate epithelial erosion appeared densely on the inferior limbus, while conjunctival ED manifested along the inferior bulbar and forniceal parts. Pseudomembrane developed early on the lower tarsal conjunctiva. A day later, ocular surface inflammation was pronounced, and the corneal ED was enlarged. The membrane became progressively thick and transformed into adhesion, which resulted in closure of the lower fornix. Lysis of adhesions of the conjunctiva was then performed, and the forniceal space was opened. PROKERA ${ }^{\circledR}$, a commercial form of amniotic membrane trapped with a PMMA ring, was also applied to cover the raw surface as a biological bandage and to promote epithelialization. Besides, PROKERA ${ }^{\circledR}$ assisted in preventing symblepharon formation in this patient, as the child's eye had not yet a fully developed size, which allowed PROKERA ${ }^{\circledR}$ to sit against and sustain the fornices (Fig. 3).

When we discovered that the inflammatory reaction in this patient was more intense than we had estimated, we increased the potency of the steroid eye drops to $1 \%$ methylprednisolone every hour and also increased the use of eye lubricants. Vitamin C 500 mg was given daily in the first week. Later, there was some evidence of new membrane development, but it eventually disappeared. Our patient's condition continuously improved, and the ED had completely healed within 1 week. Both the cornea and conjunctiva gradually became normal without fluorescein staining after 2 weeks. Then, the PROKERA ${ }^{\circledR}$ was removed. All medications could be tapered off within 4 weeks. There was no sign of limbal deficiency, and the clarity of the cornea was preserved. Forniceal space was maintained with no conjunctival fibrosis. When the patient returned for a 3-month follow-up, the cornea was still clear, and the visual acuity was $20 / 25$ (picture chart) in the affected eye (20/20 in the unaffected eye). Very mild symblepharon was noticed at the nasal side of the inferior fornix. However, the overall ocular surface looked quiet. Therefore, we did not prescribe any medications except ocular lubricants. Eventually, vision gained 20/20 at 6 months, and the minute symblepharon was stable. 


\section{Case Reports in Ophthalmology}

Case Rep Ophthalmol 2018;9:132-137

DOI: $10.1159 / 000486922$

\section{Discussion}

Chemical ocular injury is one of the most common ocular emergency conditions. Caustic agents can damage the ocular surface, resulting in several adverse outcomes that include dry eye, persistent ED, limbal stem cell deficiency, corneal scar, symblepharon, and ultimately poor vision. Prognosis varies depending on the severity of injury, the type and concentration of the chemical substance, and the contact time. The mainstays of primary management are immediate decontamination and copious irrigation. Timely and appropriate management in the early stage after injury yields less complications and improved outcomes.

Potassium permanganate ocular injury is now a rarely reported condition. Given the diminished role of $\mathrm{KMnO}_{4}$ in home and domestic use, occurrences of $\mathrm{KMnO}_{4}$ toxicity and/or injury have become rare. Therefore, some practitioners may never have encountered $\mathrm{KMnO}_{4}$ injury and would not recognize the characteristic brown discoloration of the skin or mucosa when they come into contact with $\mathrm{KMnO}_{4}$. Potassium permanganate toxicity has been reported in several publications over the past 30 years [3-5]. Some reports revealed systemic $\mathrm{KMnO}_{4}$ toxicity after ingestion, including respiratory tract obstruction, gastrointestinal damage, hepatorenal failure, and cardiovascular depression $[3,5] . \mathrm{KMnO}_{4}$ injury to the eye has also been reported $[4,6]$.

Our patient was injured by accidental contact with $\mathrm{KMnO}_{4}$ granules. Evidence of $\mathrm{KMnO}_{4}$ exposure was apparent by the brownish patches stained on fingers and toes, with confirmation upon discovery of multiple $\mathrm{KMnO}_{4}$ granules embedded in the inferior fornix of the eye, albeit we were slightly perplexed by the absence of staining on our patient's eyelids. According to its chemical properties, $\mathrm{KMnO}_{4}$ can burn human tissue. $\mathrm{KMnO}_{4}$ is a known powerful oxidizing agent [3], which causes coagulative necrosis of tissue by a process of protein denaturation and cytotoxic cell damage. Since clinical presentation and manifestations were suggestive of $\mathrm{KMnO}_{4}$ burn, standard care for chemical injury (i.e., decontamination and irrigation) was urgently given. However, some tissue staining could not be completely removed. Subsequent supportive treatment was given according to the severity of ocular injury, which was corresponding with grade 2 of the Roper-Hall classification [7]. Several publications regarding $\mathrm{KMnO}_{4}$ ocular injury reported similar management methods with good outcomes $[4,6]$. Most of those reports described $\mathrm{KMnO}_{4}$ solution-related ocular injuries, with only few reports profiling patients that had been injured by direct contact with $\mathrm{KMnO}_{4}$ crystals [8, 9].

The burn reaction in our patient was more aggressive than we had initially assumed. We postulated that a solid form of $\mathrm{KMnO}_{4}$ would have toxicity as high as concentrated $\mathrm{KMnO}_{4}$ solution. In addition, residual chemical substance within the stained tissue might continuously release $\mathrm{KMnO}_{4}$, which could contribute to additional ocular surface damage. A previous study reported successful treatment of $\mathrm{KMnO}_{4}$ ocular burn using ascorbic acid solution [10]. We have no experience with ascorbic acid treatment in this condition, and, to our knowledge, topical ascorbic acid has not been established as a standard treatment for either $\mathrm{KMnO}_{4}$ or other ocular chemical injuries. Accordingly, we followed current established protocols for the management of ocular burns and adjusted medication dosages according to our patient's condition. Vitamin C was administered orally, as it has been recommended for systemic use in burn patients with safe and effective results [11]. Adjunctive treatment with amniotic membrane, proposed by several burn-related publications [12, 13], enhances recovery by reducing inflammation and promoting wound healing.

Ocular burn from $\mathrm{KMnO}_{4}$ can be managed by treatment protocols established for burns and injuries from other chemical agents. The mainstay of treatment is still immediate and adequate decontamination. Steroid plays a major role in controlling inflammation, especially 
in the acute stage, and the dose should be adjusted according to the severity of injury. Inflammation is typically more pronounced in children than in adults, and an aggressively inflamed eye could lead to early-developed symblepharon and deformation of the ocular surface. Amniotic membrane can be effectively used as an adjunctive treatment in such severe cases. PROKERA ${ }^{\circledR}$ provides the other benefit of precluding symblepharon in particular in small eyes. Residual chemical contamination should be carefully and painstakingly removed, as missed residual contaminant or remaining nonremovable stains can cause incessant inflammation and unexpected profound ocular surface damage.

\section{Acknowledgement}

We acknowledge Anupong Veeraburinon for providing illustrations (Fig. 1-3).

\section{Statement of Ethics}

The authors have no ethical conflicts to declare.

\section{Disclosure Statement}

No conflicting relationship exists for any author.

\section{References}

1 Potassium permanganate; MSDS No. 223468; Sigma Aldrich, Singapore, November 30, 2017.

-2 Scott KJ, McGlasson WB, Roberts EA: Potassium permanganate as an ethylene absorbent in polyethylene bags to delay the ripening of bananas during storage. Aust J Exp Agric Anim Husb 1970;10:237-240.

-3 Agrawal VK, Bansal A, Kumar R, Kumawat BL, Mahajan P: Potassium permanganate toxicity: a rare case with difficult airway management and hepatic damage. Indian J Crit Care Med 2014;18:819-821.

4 Michaels DD, Zugsmith GS: Potassium permanganate burn of the eye. Eye Ear Nose Throat Mon 1973;52:97-98.

5 Johnson TB, Cassidy DD: Unintentional ingestion of potassium permanganate. Pediatr Emerg Care 2004;20:185-187.

6 Tobia S: The management of potassium permanganate ocular burn. Bull Ophthalmol Soc Egypt 1976;69:645-646.

7 Roper-Hall MJ: Thermal and chemical burns. Trans Ophthalmol Soc UK 1965;85:631-653.

-8 Meitinger A: A case of eye injury by potassium permanganate crystals. Klin Monbl Augenheilkd Augenarztl Fortbild 1953;123:493-494.

\$9 Pitter J, Vyhnanek J: Therapy of eye injuries caused by potassium permanganate crystals. Klin Monbl Augenheilkd Augenarztl Fortbild 1958;133:265-267.

$>10$ Sigg T, Leikin JB, Sigg K, Mullin T: Treatment of ocular potassium permanganate exposure with 5\% ascorbic acid solution. Ann Emerg Med 1998;32:754-755.

-11 Berger MM, Oudemans-van Straaten HM: Vitamin C supplementation in the critically ill patient. Curr Opin Clin Nutr Metab Care 2015;18:193-201.

-12 Tandon R, Gupta N, Kalaivani M, Sharma N, Titiyal JS, Vajpayee RB: Amniotic membrane transplantation as an adjunct to medical therapy in acute ocular burns. Br J Ophthalmol 2011;95:199-204.

13 Tejwani S, Kolari RS, Sangwan VS, Rao GN: Role of amniotic membrane graft for ocular chemical and thermal injuries. Cornea 2007;26:21-26. 
Chirapapaisan et al:: Ocular Injury due to Potassium Permanganate Granules

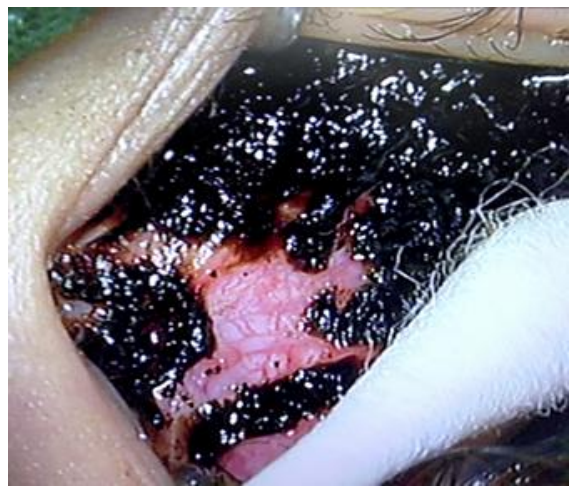

Fig. 1. Multiple semi-dissolved granules of potassium permanganate were trapped in the lower fornix.

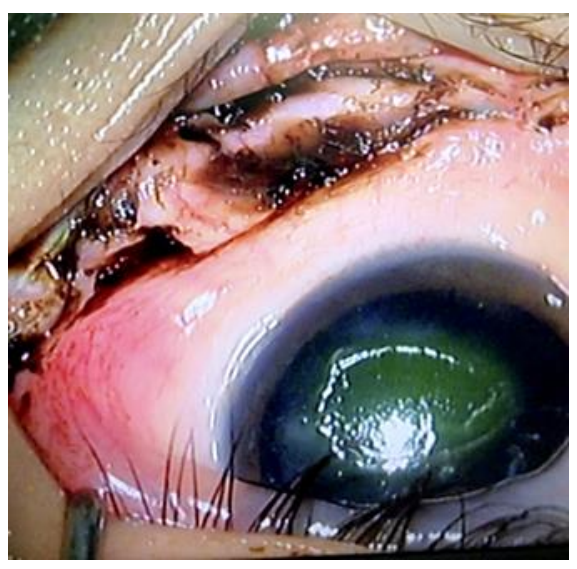

Fig. 2. After copious eye irrigation and $\mathrm{KMnO}_{4}$ granules removal, brownish stains remained on the conjunctiva and fornix. A central 5-mm corneal epithelial defect was also revealed.

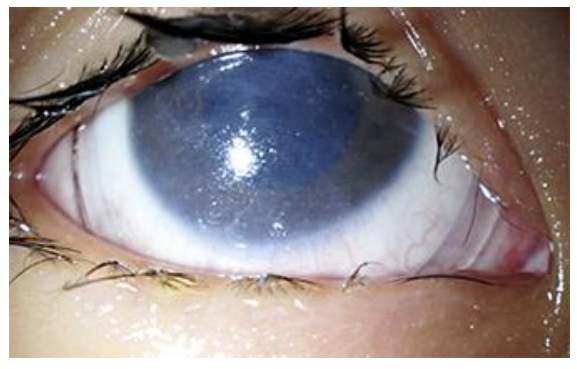

Fig. 3. Amniotic membrane enhances recovery by reducing inflammation and promoting wound healing. 